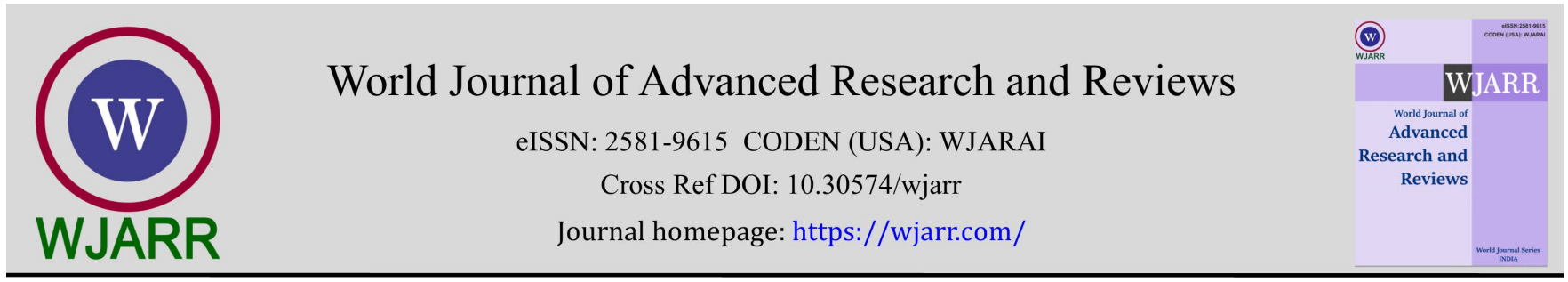

(RESEARCH ARTiCle)

Check for updates

\title{
Epidemiological, clinical and evolutionary aspects of hypotrophic newborns at term at the Mother and Child University Hospital of N'Djamena
}

\author{
Silé Souam Nguélé 1, ${ }^{*}$, Adrienne Ngaringuem ${ }^{1}$, Kounnezouné Patalet ${ }^{1}$, Kanezouné Gongnet ${ }^{1}$, Djaury Dadji-a 1 , \\ Hikdjolbo Gonzabo ${ }^{1}$ and Folquet Amorissani ${ }^{2}$
}

${ }^{1}$ Department of paediatrics, Mother and Child University Hospital, N'Djamena-Chad.

2 Department of paediatrics - University of Abidjan- Ivory Coast.

World Journal of Advanced Research and Reviews, 2021, 13(01), 180-188

Publication history: Received on 29 November 2021; revised on 05 January 2022; accepted on 07 January 2022

Article DOI: https://doi.org/10.30574/wjarr.2022.13.1.0764

\begin{abstract}
Introduction: Hypotrophy is a public health problem in developing countries. Its etiology is multifactorial and it may be associated with high morbidity and mortality. The objective of this study was to describe the epidemiological, clinical and evolutionary profile of hypotrophic newborns at term.

Methodology: this was a prospective, descriptive and analytical study conducted in the neonatology department of the MCUH of N'Djamena from 01/06/2018 to 31/05/2019. It involved 109 hypotrophic newborns at term hospitalized.

Results: The frequency of hypotrophy was 7.8\%, the risk factors were: housewife status (81.7\%), low level of education $(67 \%)$, poor pregnancy follow-up $(59.7 \%)$, malaria $(40.4 \%)$, urogenital infections $(22 \%)$ and anemia $(22 \%)$ during pregnancy. Hypotrophy was harmonious in $58.7 \%$ of cases, the sex ratio was 1.14 and visible congenital malformations were observed in $12.7 \%$ of cases. The main reasons for hospitalization were neonatal infections (64.2\%), perinatal asphyxia (14.7\%) and hypothermia (11.9\%). Lethality was $16.5 \%$ and associated with multiparity, poor pregnancy follow-up, vaginal delivery, home delivery, pathological Apgar score, notion of resuscitation, existence of malformation, respiratory distress and perinatal asphyxia.
\end{abstract}

Conclusion: Better monitoring of pregnancy, use of family planning by couples, delivery in an institutionalized setting, and reinforcement of the technical platform of the neonatology department will reduce neonatal morbidity and mortality related to hypotrophy.

Keywords: Newborn; Hypotrophy; Etiology; Evolution; N'Djamena

\section{Introduction}

According to the World Health Organization, birth weight is an important indicator of child health because of the relationship between this variable and infant morbidity and mortality [1]. Not only does it allow an a posteriori estimate of the harmonious growth in utero, but it could also be a determinant marker of risk of disease in adulthood [2]. Defined as a birth weight of less than 2 standard deviations or less than the 10th percentile compared to the general population, i.e. less than $2500 \mathrm{~g}$ at term $[1,3,4]$, low birth weight is a major public health problem in both developing and developed countries because of its high prevalence and the resulting neonatal consequences. Its prevalence is estimated at $16.5 \%$ in developing countries compared to 7\% in developed countries [6]. In Chad, according to the 2014-2015 Demographic Health and Multiple Indicator Survey, the low birth weight rate is 7\% nationally [7].

\footnotetext{
* Corresponding author: Silé Souam Nguélé

Department of paediatrics, Mother and Child University Hospital, N’Djamena-Chad.

Copyright $(2022$ Author(s) retain the copyright of this article. This article is published under the terms of the Creative Commons Attribution Liscense 4.0.
} 
Many factors are involved in the occurrence of hypotrophy as reported by various African authors [3,8-10] and the clinical picture is made of two clinical forms: harmonious hypotrophy and disharmonious hypotrophy.

In many countries with limited resources, such as Chad, there is no specific program for the care of these newborns and the lack of technical facilities could be the cause of the excess mortality of hypotrophic babies. A study carried out on prematurity showed a high mortality rate of $42.4 \%$ in relation to the perinatal and neonatal characteristics of the newborns but also to the delay in their care [4]. The situation of hypotrophic babies born at term is poorly documented, whereas a more precise knowledge of this condition and its evolution in the Chadian context characterized by poor health coverage will allow for better actions to be initiated. With this in mind, and given the scarcity of studies devoted to this subject, the present study aims to describe the epidemiological, clinical and evolutionary aspects of hypotrophic full-term babies hospitalized and followed in the neonatology department of the Mother and Child University Hospital (MCUH) in N'Djamena, in order to contribute to the improvement of their care.

\section{Patients and methods}

\subsection{Study design and study population}

This was a prospective, descriptive and analytical study conducted in the neonatology department of the MCUH of N'Djamena from June 1, 2018 to May 31, 2019. It involved all hypotrophic newborns born at term and admitted to the MCUH neonatology department during the inclusion period.

Full-term newborns (gestational age $\geq 37$ weeks of amenorrhea) with a birth weight of less than 2500 , admitted within 72 hours of delivery, and whose parents were consenting were included. Preterm infants, hypotrophs whose parents refused hospitalization or were discharged against medical advice, and those in whom parental consent was not obtained were not included in the study.

Sampling was comprehensive and non-probability based with consecutive recruitment of incident cases during the study period.

\subsection{Data collection}

Data from the interview, clinical examination on admission, during hospitalization and follow-up were recorded on a predefined collection form. Biological data were collected on the basis of available results. Other sources of data were the patient admission registers and hospitalization records.

In neonatology, newborns were treated according to the neonatal complication associated with hypotrophy. Stabilized neonates weighing less than $2000 \mathrm{~g}$ were reared by the mother-kangaroo method. Follow-up after hospitalization was done at 1 week, 2 weeks and 1 month. It consisted of taking anthropometric parameters and looking for medical complications.

The variables considered were socio-demographic (mother's age, mother's level of education, maternal socioprofessional status, residence) related to the course of pregnancy (pregnancy follow-up, maternal pathologies during pregnancy, parity, history of low birth weight) and delivery (uterine height, delivery site, mode of delivery, number of fetuses), relative to the newborn (sex, anthropometric parameters, type of hypotrophy, Apgar score, existence and type of visible malformation, anthropometric parameters at birth, neonatal complications) and evolutionary (death, length of stay, complications during follow-up, anthropometric parameters at the end of follow-up).

\subsection{Ethics}

From an ethical point of view, a favorable opinion from the ethics committee of the Faculty of Human Health Sciences, an administrative authorization from the management of the MCUH, as well as a verbal consent from the parents of the newborn were obtained. The study did not involve any risk to the patients; the confidentiality of the data collected was respected.

\subsection{Statistical analysis}

The collected data were entered and analyzed using SPSS 18 and Epi info 7 software. A descriptive analysis was performed with calculation of the hospital incidence of hypotophia, the absolute number and percentage for qualitative variables and the mean with its standard deviation for quantitative variables. 
A bivariate analysis was performed to assess the association between maternal sociodemographic characteristics, obstetric characteristics, neonatal characteristics, and newborn death during follow-up by calculating the relative risk (RR) with its 95\% confidence interval (CI95\%). The chi-square test (or Fisher's exact test) was used to compare proportions with a $\mathrm{p}<0.05$ significance level

\section{Results}

\subsection{Frequency}

During the study period, 1392 newborns were hospitalized in the neonatology department of the CHU-ME for various pathologies, 109 of whom suffered from hypotrophy, i.e., a hospital frequency of $7.8 \%$.

\subsection{Characteristics of mothers of hypotrophic newborns}

The mothers of the hypotrophic newborns were housewives (81.7\%), students (10.7\%), students (5.5\%) and civil servants $(2.7 \%)$. Their average age was $25.5 \pm 7$ years with extremes of 16 and 40 years. The 16-18 age group represented $26.6 \%$ of the cases, the $19-35$ age group $53.2 \%$ and the over 35 age group $20.2 \%$. The mothers were uneducated in $36.7 \%$ of cases, primary school in $30.3 \%$, and secondary school in $24.8 \%$ and higher education in $8.2 \%$. They lived in urban areas in $80.7 \%$ of cases and in rural areas in $19.3 \%$ of cases.

Pregnancy follow-up was absent in $13.8 \%$ of cases, insufficient in $45.9 \%$ and normal in $40.3 \%$. Multiparity was found in $52.3 \%$ of cases, primiparity in $26.6 \%$ and pauciparity in $21.1 \%$. A history of low birth weight delivery was found in $14.7 \%$ of mothers.

The main maternal pathologies causing hypotrophy were malaria (40.4\%), urogenital infections (22\%) and pregnancy anemia (11\%). Other pathologies were: pre-eclampsia/eclampsia (5.5\%), hemorrhage (2.8\%), toxoplasmosis $(0.9 \%)$, rubella (0.9\%), and syphilis $(0.9 \%)$. Seventeen mothers $(15.6 \%)$ had not presented any pathology during the pregnancy.

Delivery took place in a health facility in $88.1 \%$ of cases and at home in $11.9 \%$ of cases. Uterine height was less than 30 $\mathrm{cm}$ in $56 \%$ of cases. Delivery was by vaginal route in $87.2 \%$ of cases. Multiple pregnancy was involved in $34.9 \%$ of hypotrophy.

\subsection{Clinical characteristics of hypotrophic newborns}

Males represented 53.2\% ( $n=58)$ of the cases and females $46.8 \%(n=51)$, i.e. a sex ratio of 1.14 .

The average anthropometric parameters at admission were:

- Weight: $1950 \pm 398.7 \mathrm{~g}$ with extremes of 1000 and $2470 \mathrm{~g}$;

- Height: $45.5 \pm 2.9 \mathrm{~cm}$ with extremes of 40 and $51 \mathrm{~cm}$;

- $\quad$ Head circumference: $32.2 \pm 2.5 \mathrm{~cm}$ with extremes of 26 and $37 \mathrm{~cm}$.

On admission, $54.1 \%$ of the hypotrophs had at least $2000 \mathrm{~g}$; hypotrophy was harmonious in $58.7 \%$ of the cases and the newborns had been resuscitated in $22 \%$ of the cases (Table 1 )

Table 1 Distribution of hypotrophic newborns by characteristics at admission $(n=109)$

\begin{tabular}{|l|c|c|}
\hline Variable & n & \% \\
\hline Birth weight (g) & 17 & 15.6 \\
\hline $1000-1499$ & 33 & 30.3 \\
\hline $1500-1999$ & 59 & 54.1 \\
\hline$\geq 2000$ & 81 & 74.3 \\
\hline Head circumference (cm) & 28 & 25.7 \\
\hline$<35$ & \multicolumn{2}{|l}{} \\
\hline$\geq 35$ &
\end{tabular}




\begin{tabular}{|l|l|l|}
\hline$<47$ & 64 & 58.7 \\
\hline$\geq 47$ & 45 & 41.3 \\
\hline Type of hypotrophy & \multicolumn{3}{|l|}{} \\
\hline Harmonious hypotrophy & 64 & 58.7 \\
\hline Disharmonious hypotrophy & 45 & 41.3 \\
\hline Apgar score at 5 minutes \\
\hline$\leq 7$ & 12 & 11 \\
\hline$>7$ & 84 & 77.1 \\
\hline Unknown & 13 & 11.9 \\
\hline Resuscitation & \multicolumn{2}{|l}{} \\
\hline Yes & 24 & 22 \\
\hline No & 85 & 78 \\
\hline
\end{tabular}

Malformations were found in 14 hypotrophic newborns, i.e. $12.8 \%$ of the cases. These were 5 cases of polymalformative syndrome, 2 cases of hypospadias, 7 cases of cleft lip and palate, facial dysmorphism, microcephaly, spina bifida, omphalocele, laparoschisis and polydactyly.

Neonatal infection was the main complication found (64.2\%) followed by perinatal asphyxia (14.7\%) and hypothermia $(11.9 \%)$. Other complications were: neonatal anemia (5.5\%), neonatal respiratory distress $(2.8 \%)$ and hypocalcemia $(0.9 \%)$.

\subsection{Evolution of hypotrophic newborns}

The average length of stay was $5.9 \pm 3$ days with extremes of 1 and 21 days. It was less than or equal to 7 days in 82 cases (75.2\%) and greater than 7 days in 27 cases $(24.8 \%)$.

Table 2 Evolution of hypotrophic newborns according to the socio-demographic and obstetrical characteristics of the mothers $(\mathrm{N}=109)$

\begin{tabular}{|c|c|c|c|c|c|c|}
\hline \multicolumn{2}{|l|}{ Characteristics } & \multicolumn{2}{|c|}{ Death } & \multirow[t]{2}{*}{$\mathbf{R R}$} & \multirow[t]{2}{*}{$\mathrm{CI}_{95 \%}$} & \multirow[t]{2}{*}{$\mathbf{p}$} \\
\hline & & Yes & No & & & \\
\hline \multirow[t]{2}{*}{ Age } & $\leq 18$ or $>35$ & $9(18 \%)$ & $42(82 \%)$ & 1.1 & {$[0.5 ; 2.6]$} & 0.8 \\
\hline & $19-35$ & $9(16 \%)$ & $49(84 \%)$ & & & \\
\hline \multirow[t]{2}{*}{ Level of education } & None/primary & $12(16 \%)$ & $61(84 \%)$ & 0.99 & {$[0.4 ; 2.4]$} & 0.9 \\
\hline & High school and above & $6(17 \%)$ & $30(83 \%)$ & & & \\
\hline \multirow[t]{2}{*}{ Residence } & Rural & $3(14 \%)$ & $18(86 \%)$ & 0.8 & {$[0.3 ; 2.6]$} & 0.8 \\
\hline & Urban & $15(17 \%)$ & $73(83 \%)$ & & & \\
\hline \multirow[t]{2}{*}{ Primiparity } & Yes & $5(17 \%)$ & $24(83 \%)$ & 1.1 & {$[0.4 ; 2.7]$} & 0.9 \\
\hline & No & $13(16 \%)$ & $67(84 \%)$ & & & \\
\hline \multirow[t]{2}{*}{ Multiparity } & Yes & $11(19 \%)$ & $46(81 \%)$ & 1.4 & {$[0.6 ; 3.4]$} & 0.4 \\
\hline & No & $7(13 \%)$ & $45(87 \%)$ & & & \\
\hline \multirow[t]{2}{*}{ Mode of delivery } & Low route & $16(17 \%)$ & $79(83 \%)$ & 1.2 & {$[0.3 ; 4.6]$} & 0.8 \\
\hline & Cesarean section & $2(14 \%)$ & $12(86 \%)$ & & & \\
\hline \multirow[t]{2}{*}{ Place of delivery } & Home & $4(31 \%)$ & $9(69 \%)$ & 2.1 & {$[0.8 ; 5.4]$} & 0.2 \\
\hline & health facility & $14(15 \%)$ & $82(85 \%)$ & & & \\
\hline \multirow[t]{2}{*}{ ANC } & $0-3$ & $13(20 \%)$ & $52(80 \%)$ & 1.8 & {$[0.7 ; 4.6]$} & 0.2 \\
\hline & $\geq 4$ & $5(11 \%)$ & $39(89 \%)$ & & & \\
\hline
\end{tabular}


The average anthropometric parameters at discharge were

- Weight: $2025 \pm 367.4 \mathrm{~g}$ with extremes of 1060 and $2950 \mathrm{~g}$;

- Height: $45.9 \pm 2.8 \mathrm{~cm}$ with extremes of 39 and $51 \mathrm{~cm}$

- Head circumference: $32.7 \pm 2.4 \mathrm{~cm}$ with extremes of 26 and $39 \mathrm{~cm}$.

After the first hospitalization, 13 newborns presented complications during the month following the return home, of which 6 were rehospitalized. The main complications were: strangulated inguinal hernia (1), anemia (1), hyperthermia (2), late neonatal infection (6), rhinitis (3).

Eighteen (18) hypotrophic neonates died during the study period representing a case fatality of $16.5 \%$. Deaths occurred during the first week of hospitalization in 10 cases and after 7 days in 8 cases.

The risk of death of hypotrophic newborns was high when the mothers were younger than 18 years or older than 35 years $(R R=1.1)$, in case of multiparity $(R R=1.4)$, vaginal delivery $(R R=1.2$ ), home delivery $(R R=2.1)$, and poor pregnancy follow-up ( $R R=1.8)$, but the association was not statistically significant (Table 2).

The risk of death of hypotrophic newborns was also high in case of male sex (RR = 1.4), weight less than $2000 \mathrm{~g}$ ( $\mathrm{RR}=$ $1.2)$, pathological Apgar score at the 5th minute $(R R=2.3)$, resuscitation at birth or admission $(R R=1.8)$, malformation $(R R=1.4)$, perinatal asphyxia $(R R=2.2)$, and neonatal respiratory distress $(R R=4.4)$, but the association was not statistically significant (Table 3 ).

Table 3 Evolution of hypotrophic newborns according to neonatal characteristics $(n=109)$

\begin{tabular}{|l|l|c|c|c|c|c|}
\hline \multirow{2}{*}{ Characteristics } & & \multicolumn{2}{|c|}{ Death } & RR & CI95\% & p \\
\hline \multirow{2}{*}{ Sex } & & Yes & No & & & \\
\hline \multirow{2}{*}{ Weight (g) } & Fale & $11(19 \%)$ & $47(81 \%)$ & 1.4 & {$[0.6 ; 3.3]$} & 0.5 \\
\cline { 2 - 8 } & $<2000$ & $9(18 \%)$ & $41(82 \%)$ & 1.2 & {$[0.5 ; 2.7]$} & 0.7 \\
\cline { 2 - 8 } & $\geq 2000$ & $9(15 \%)$ & $50(85 \%)$ & & & \\
\hline \multirow{2}{*}{ Apgar pathology } & Yes & $4(33 \%)$ & $8(67 \%)$ & 2.3 & {$[0.9 ; 5.9]$} & 0.1 \\
\cline { 2 - 8 } & No & $14(14 \%)$ & $83(86 \%)$ & & & \\
\hline \multirow{2}{*}{ Resuscitation } & Yes & $6(25 \%)$ & $18(75 \%)$ & 1.8 & {$[0.7 ; 4.2]$} & 0.2 \\
\cline { 2 - 8 } & No & $12(14 \%)$ & $73(86 \%)$ & & & \\
\hline Malformation & Yes & $3(21 \%)$ & $11(79 \%)$ & 1.4 & {$[0.4 ; 4.1]$} & 0.6 \\
\hline \multirow{2}{*}{ Neonatal infection } & No & $15(16 \%)$ & $80(84 \%)$ & & & \\
\hline \multirow{2}{*}{ Yes } & $10(14 \%)$ & $60(86 \%)$ & 0.7 & {$[0.3 ; 1.6]$} & 0.4 \\
\hline No & $8(21 \%)$ & $31(79 \%)$ & & & \\
\hline Respiratory distress & Yes & $2(67 \%)$ & $1(33 \%)$ & 4.4 & {$[1.8 ; 11]$} & 0.07 \\
\hline & No & $16(15 \%)$ & $90(85 \%)$ & & & \\
\hline Yes & $5(31 \%)$ & $11(69 \%)$ & 2.2 & {$[0.9 ; 5.4]$} & 0.08 \\
\hline & Yes & $1(17 \%)$ & $5(83 \%)$ & 1 & {$[0.2 ; 6.4]$} & 1 \\
\hline
\end{tabular}

\section{Discussion}

The main results show that hypotrophy at term is frequent in the neonatology department, particularly in its harmonious form. Its occurrence is favored by maternal factors and its outcome marked by a high lethality is a function of both the characteristics of the newborn and those of the mother. 
Analysis of the data from this study shows that the hospital frequency of hypotrophy at term in newborns is $7.8 \%$ in the neonatology department of the MCUH of N'Djamena. Compared to data from other authors, it is close to the 7\% observed by Kakudji et al in Lubumbashi (DRC) in 2017 [11], higher than the $5.6 \%$ and $4.8 \%$ observed respectively by Lataief in Tunisia and Yao in Ivory Coast in $2015[1,5]$. However, this frequency is lower than those found by Gueye and al in Senegal in 2012 (12.8\%), Kaboré and al in Burkina Faso in 2007 (12.4\%) [9, 12]. Although there is a disparity of figures between the different studies, the results all converge towards the conclusion that low birth weight remains a public health problem in African countries. As low birth weight is recognized as a poor prognostic factor by various authors $[4,13,14]$, a high proportion in a hospital setting with limited technical facilities probably contributes to the still high neonatal and infant mortality rate in Chad [7].

From an etiological point of view, socio-demographic factors such as maternal age, housewife status and low level of education could be factors favoring low birth weight because of the observations made in this study. However, their real implication could only be highlighted in an analytical study as reported by other authors [15-17].

Indeed, the analysis of the data of the present study shows that the hypotrophic newborns were mostly born to relatively young mothers as reported by other authors $[9,12,18,19]$. These mothers were largely housewives with no consistent source of income. Their low socio-economic level, their daily workload in the Chadian context, and the low level of education observed in the present study could be one of the explanations for the late admissions and the problems encountered in the care of the newborns.

At the obstetrical level, the absence or poor monitoring of pregnancy, multiparity, multiple pregnancies, a history of low birth weight deliveries, and maternal pathologies were reported in varying proportions, as is the case in other studies $[15-17,20]$.

Regarding pregnancy monitoring, low birth weight neonates were from pregnancies that were not or poorly monitored in 59.7\% of cases, figures comparable to those reported by Mungyeh and al in 2017 in Cameroon, i.e. 57.5\% of cases [21]. Multiparity represented $52.3 \%$ of cases. This result is higher than that reported by Kaboré and al in Burkina Faso $(35.2 \%)[12]$.

The main pathologies that could be the cause of hypotrophy in the neonatology department of the MCUH were malaria, urogenital infections and anemia during pregnancy. These results are corroborated by those of Yao and al at the CHU of Treichville in 2015 who concluded that malaria access, urogenital infections and anemia were the main risk factors for hypotrophy [5].

Uterine height, a predictor of fetal weight during pregnancy, was less than $30 \mathrm{~cm}$ in the majority of cases. Delivery was by vaginal route and in a health facility in most cases as reported by other authors [1,21]. Twinning accounted for $34.9 \%$ of cases.

Clinically, the newborns were male in $53.2 \%$ of cases. This finding is in line with the observations made by Assé and al in 2016 in Côte d'Ivoire and Adjahoto and al in 1999 in Togo [22, 23], which emphasize a predominance of male sex without its role being clearly elucidated. The average anthropometric parameters at birth were low without being extremely small and were close to those reported by Demmouche and al in 2015 in Algeria and Assé et al [8, 22].

Birth weight is a prognostic factor in neonatology, its smaller value is associated with a higher risk of death according to various authors $[4,14]$. The analysis of the data of the present study shows that $54.1 \%$ of hypotrophic newborns had a weight of more than $2000 \mathrm{~g}$, which is a lower risk situation. Thus, these babies were not eligible for maternal kangaroo care whose contribution to the growth of low birth weight babies was demonstrated by Souam Nguelé and al in 2020 at the MCUH in N'Djamena [13].

Hypotrophy was harmonious or proportional in $58.7 \%$ of the newborns included in this study. In the other newborns, only the weight was below normal. This observation is contrary to that made by Mungyeh et al in Yaoundé in 2017 where a predominance of disharmonious hypotrophy of the order of $74 \%$ was found [21].

Newborns were hospitalized for various complications associated with hypotrophy. In $12.8 \%$ of them, a visible malformation was found. This result is much higher than that of Jedidi et al in whom malformations represented only $0.6 \%$ of cases [2]. Poor pregnancy monitoring and the use of self-medication could explain the high frequency of malformations observed in N'Djamena. Other complications that led to the hospitalization of hypotrophic newborns in the neonatology department of the MCUH of N'Djamena were neonatal infection, perinatal asphyxia and hypothermia. These results are similar to those reported by Mungyeh and al [21]. 
Evolutionarily, the neonates had a relatively short length of stay. The main complications during the first month after discharge were strangulated inguinal hernia, anemia, isolated hyperthermia, malaria, late neonatal infection, cutaneous staphylococcal disease and rhinitis. These complications are not specific to hypotrophic infants born at term since they have also been found in preterm infants by Gongnet and al [24] and could be detrimental to their outcome because of the associated low weight.

The case fatality at the end of follow-up was 16.5\%. Although lower than that observed by Mungyeh and al (34.6\%) [21], this case fatality remains high and contributes to the high neonatal and infant mortality rate in Chad [7].

The search for prognostic factors led to the conclusion that certain socio-demographic and obstetrical characteristics of the mothers as well as certain neonatal characteristics were associated with a higher risk of death without the statistical association being significant. These prognostic factors are potential in the Chadian context; their role has also been demonstrated in other countries $[9,22,25]$. A multicenter study with a large number of subjects should be conducted to confirm or refute their prognostic value in Chad.

Among the maternal characteristics, extreme ages, multiparity, poor pregnancy monitoring, vaginal delivery and home delivery were associated with a high risk of death. The association between these different factors and death of hypotrophic newborns has been demonstrated by other authors $[9,22]$.

Regarding the specific characteristics of newborns, male sex, a weight of less than $2000 \mathrm{~g}$, a pathological Apgar score and the notion of resuscitation were associated but not statistically significant with a high risk of death. These different factors have been reported by various authors $[1,4,5,9,22,25]$. Similarly, the presence of malformation, respiratory distress and perinatal asphyxia were associated but not significantly with death in hypotropic newborns.

\section{Conclusion}

Hypotrophy is frequent at the MCUH of N'Djamena representing 7.8\% of hospitalizations in the neonatology department. Its occurrence is favored by certain characteristics: young maternal age, low socio-economic and educational level, poor pregnancy follow-up, malaria, urogenital infections and anemia during pregnancy.

More than half of the newborns had harmonious hypotrophy and $13 \%$ of them had visible congenital malformations. The main complications that led to hospitalization were neonatal infections, perinatal asphyxia and hypothermia.

Lethality was high and potentially related to maternal age, multiparity, poor pregnancy monitoring, vaginal delivery, home delivery, pathological Apgar score, notion of resuscitation, existence of malformation, respiratory distress and perinatal asphyxia.

The improvement of women's living conditions, a better monitoring of pregnancy, the adoption of family planning by couples, delivery in an institutionalized setting, as well as the reinforcement of the technical facilities of maternity hospitals and neonatology services will allow for better management and a reduction in neonatal morbidity and mortality.

\section{Compliance with ethical standards}

\section{Acknowledgments}

The favorable opinion of the ethics committee of the Faculty of Human Health Sciences of the University of N'Djamena, the authorization of the management of the MCUH have been obtained.

\section{Disclosure of conflict of interest}

There are no conflicts of interest in connection with this paper

\section{Statement of informed consent}

Informed parental consent was obtained for all participants included in this study. 


\section{References}

[1] Letaief M, Soltani MS, Ben KS, Bechir A. Epidemiology of low birth weight in the Tunisian Sahel. Santé Publique. 2001; 13(4): 359-66.

[2] Jedidi J, Yaih S, Feki H, Khassis M, Guermazi M, Gargouri A et al: Intrauterine growth retardation: definition, epidemiology and risk factors: particularities of the Sfax Governorate. JIM Sfax. 2010; (19/20): 20-9.

[3] Gold F, Jouannic JM, Mitanchez-Mokhtari D. Intrauterine growth retardation. Encycl Med Chir (Elsevier Masson SAS, Paris), Pediatrics-Infectious Diseases. 2010; 4-002-S-80: 10.

[4] Souam Nguelé S, Gongnet K, Gabkika BM, Toralta J, Granga DD, Youssouf Hagré D, et al. Factors associated with survival of the preterm newborn at the Mother and Child Hospital of N'Djamena in Chad. J Afr Pediatr Genet Med. 2018; (4): 15-21.

[5] Yao I, Guie P, Dia JM, Bohoussou PE, N'guessan E, Saki C, et al. Low birth weight children born at term: epidemiological characteristics and maternal risk factors at Treichville University Hospital (Abidjan-Cote d'Ivoire). Med Afr Noire. 2015; 62(12): 575-80.

[6] UNICEF, WHO. Low birth weight: country, regional and global estimates. New York: UNICEF. 2004.

[7] Institut National de la Statistique, des Études Économiques et Démographiques (INSEED), Ministère de la Santé Publique (MSP) and ICF International, 2014-2015. Chad Multiple Indicator Demographic and Health Survey (DHS-MICS 2014-2015). Rockville, Maryland, USA: INSEED, MSP and ICF International. 201 6.

[8] Camara B, Diack B, Diouf S, Signate/Sy H, Sall MG, Bam, Sarr M, Hanne MK, Thia C, Diouf L, Sow D, Fall M. Low birth weight, frequency and risk factors in the District of GUEDIAWAYE (Ban-lieu de Dakar-Senegal). Med Afr Noire. 1996; 43(5): 260-5.

[9] Gueye M, Diallo D, Sylla A, Faye PM, Gueye N R, Cisse Bathily A, Seye PI, Ndiaye O. Epidemiological and prognostic aspects in the neonatology department of the Abass Ndo center in Dakar, Senegal. Med Afr Noire. 2012; 59(3): 119-24.

[10] Demmouche A, Benali AI, Ghani AE, Mai H, Beddek H, Chala lH, et al. Etiology of low birth weight at the maternity ward of sidi Bel Abbes (western Algeria). Antropo. 2015; 33: 103-9.

[11] Kakudji LP, Mukuku O, Mwembo Tambwe A, Kalenga Muenze KP. Study of maternal and perinatal prognosis during adolescent delivery in Lubumbashi, Democratic Republic of Congo. Pan African Med J. $2017 ; 26: 182$.

[12] Kaboré P, Donnen P, Dramaix-Wilmet M: Obstetrical risk factors for low birth weight at term in rural Sahel. Santé Publique. 2007; 19(6): 489-97.

[13] Souam Nguelé S, Yibé P, NGaringuem A, Gongnet K, Gonzabo H, Toralta J, Brahim Boy O. Management of preterm and low birth weight newborns by the "kangaroo mother" method. J Afr Pediatr Genet Med. 2020; (10): 16-20.

[14] Marchant T, Willey B, Katz J, Clarke S, Kariuki S. Neonatal Mortality Risk Associated with Preterm Birth in East Africa, Adjusted by Weight for Gestational Age: Individual Participant Level Meta-Analysis. PLOS Med. 2012; 9(8): e1001292.

[15] Leno D W A, Camara MK, Kouyaté. S, Diallo FD, Tolno J, Hijazy Y, et al: Maternal determinants associated with low weight for gestational age at the maternity ward of Donka Hospital in Conakry. Rev Med Perinat. 2017; 9: 17883.

[16] Kotabal Rajashree, Hebballil Prashanth, Ratnagaran Revathy: Study on the factors associated with low birth weight among newborn delivered in a tertiary-care hospital, shimoga, Karnataka. International J Med Sci Public Health. 2015; 4(9): 1-4.

[17] Kangula IB, Kikolo Ngoy U E, Kabamba Nzaji M, Kalenga Mwenze KP. Risk factors for low birth weight in Semirural Kamina, Democratic Republic of Congo. Pan African Med J. 2014; 17: 220.

[18] Milabyo KP. Low birth weight in Maniema Democratic Republic of Congo. Public Health. 2006; 16 : 103 -7.

[19] Luhete KP, Mukuku O, Kalenga PMK: Study of low birth weight associated with maternal age and parity in a mother-infant couple population followed in Lubumbashi. Pan Afr Med J. 2015; 1-9.

[20] Gopalan Sarala. Low Birth Weight Causes, consequences and Interventions to Achieve Reduction. Proc Indian Natn Sci Acad. 2018; 84; 843-51. 
[21] Mungyeh Mah E, Chiabi A, Doualla Ejake L, Nguefack S, Mbassi AWA H, Ngouanou D, et al. Frequency and risk factors of intrauterine growth retardation at the Yaoundé Gyneco-Obstetric and Pediatric Hospital. Health Sci Dis. 2017; 18(4): 73-7.

[22] Asse KV, Aka Ka, Yenan J, Yeboua KR, Yao KC, Avi C et al. Low birth weight at the University Hospital of BOUAKE (Ivory Coast): a retrospective study about 179 cases. Rev Int Sci Med. 2016; 18(4): 269-74.

[23] Adjahoto E O, Djossou K P, Hodonu K A S. Prediction of hypotrophy by uterine height in the department of gynecology-obstetrics of the Centre Hospitalier Universitaire-Tokoin-Lomé (Togo). J Gynecol Obstet Biol Reprod. 1999; 28: 352-7.

[24] Gongnet K, Souam Nguelé S, Gonzabo H. Medical outcome and post-natal growth approach of premature infant in ambulatory follow-up in N'Djamena (Chad). World Journal of Advanced Research and Reviews. 2021; 09(01): 256-61.

[25] Ilunga AM, Mukuku O, Mawaw PM, Mutombo A M, Lubala T k, et al: Frequency and Early Neonatal Prognosis of Low Birth Weight in Lubumbashi, Democratic Republic of Congo. Pan African Med J. 2016; 1-8. 